\title{
man \\ Quinolizidine-Based Variations and Antifungal Activity of Eight Lupinus Species Grown under Greenhouse Conditions
}

\author{
Willy Cely-Veloza *, Diego Quiroga $\mathbb{D}$ and Ericsson Coy-Barrera *
}

Bioorganic Chemistry Laboratory, Facultad de Ciencias Básicas y Aplicadas, Universidad Militar Nueva Granada, Cajica 250247, Colombia; diego.quiroga@unimilitar.edu.co

* Correspondence: u7700102@unimilitar.edu.co (W.C.-V.); ericsson.coy@unimilitar.edu.co (E.C.-B.)

check for updates

Citation: Cely-Veloza, W.; Quiroga,

D.; Coy-Barrera, E.

Quinolizidine-Based Variations and Antifungal Activity of Eight Lupinus Species Grown under Greenhouse Conditions. Molecules 2022, 27, 305. https://doi.org/10.3390/

molecules27010305

Academic Editors: Asta Judžentienè and Kristina Ložienè

Received: 25 November 2021

Accepted: 30 December 2021

Published: 4 January 2022

Publisher's Note: MDPI stays neutral with regard to jurisdictional claims in published maps and institutional affiliations.

Copyright: (C) 2022 by the authors. Licensee MDPI, Basel, Switzerland. This article is an open access article distributed under the terms and conditions of the Creative Commons Attribution (CC BY) license (https:// creativecommons.org/licenses/by/ $4.0 /)$.

\begin{abstract}
Fusarium oxysporum is an aggressive phytopathogen that affects various plant species, resulting in extensive local and global economic losses. Therefore, the search for competent alternatives is a constant pursuit. Quinolizidine alkaloids (QA) are naturally occurring compounds with diverse biological activities. The structural diversity of quinolizidines is mainly contributed by species of the family Fabaceae, particularly the genus Lupinus. This quinolizidine-based chemo diversity can be explored to find antifungals and even mixtures to address concomitant effects on $F$. oxysporum. Thus, the antifungal activity of quinolizidine-rich extracts (QREs) from the leaves of eight greenhouse-propagated Lupinus species was evaluated to outline promising QA mixtures against F. oxysporum. Thirteen main compounds were identified and quantified using an external standard. Quantitative analysis revealed different contents per quinolizidine depending on the Lupinus plant, ranging from 0.003 to $32.8 \mathrm{mg} / \mathrm{g}$ fresh leaves. Bioautography showed that all extracts were active at the maximum concentration $(5 \mu \mathrm{g} / \mu \mathrm{L})$. They also exhibited $>50 \%$ mycelium growth inhibition. All QREs were fungistatic except for the fungicidal QRE of L. polyphyllus Lindl. Angustifoline, matrine, $13 \alpha$-hydroxylupanine, and 17-oxolupanine were ranked to act jointly against the phytopathogen. Our findings constitute reference information to better understand the antifungal activity of naturally afforded QA mixtures from these globally important plants.
\end{abstract}

Keywords: Fabaceae; Lupinus; quinolizidines; alkaloids; Fusarium oxysporum; antifungals

\section{Introduction}

Fabaceae is the second largest family of flowering plants, containing approximately 490 species that have been used for medicinal purposes [1]. These plants are distributed in more than 65 genera of Fabaceae and can produce specialized metabolites such as quinolizidine alkaloid (QAs) (specially Genisteae Tribe) and non-nitrogenous compounds [2,3]. One of these genera is Lupinus, which is distributed in the Mediterranean, North and East Africa, and North and South America, and hosts the largest number of species [4]. About 170 Lupinus species can be found worldwide, including wild and domestic plants, widely called lupins [5]. In Colombia, 47 Lupinus species have been reported in the central and eastern mountain ranges in the Colombian Massif and Sierra Nevada de Santa Marta [6]. Lupinus-based products, particularly lupin seed proteins, are becoming good alternatives for multiple foods, including beverages, bakery, imitation meat, and dairy products, which have promoted intensive lupin cultivation in several parts of the world to produce grain protein [7]. However, the presence of QAs in lupin seed-based products provides a bitter taste. Therefore, debittering procedures should be performed on lupin seeds containing high QA contents for human and animal consumption [8].

Lupinus is one of the genera of Fabaceae that shows more considerable variability in QAs, which are biosynthesized by the L-lysine pathway in aerial green tissues, particularly leaves, and translocated to all plant parts whose accumulation is mainly in seeds (4$8 \%$ dry weight) [9]. Above 170 QAs have been detected, identified, and quantified in 
different Lupinus species from which bicyclic-, tricyclic-, and tetracyclic-type QAs can be obtained [10-13] and whose structural pattern is highly variable depending on the species [14]. The QA biosynthesis is highly regulated, influenced by genetic (e.g., genotype), biotic (e.g., presence of phytophagous insects and/or microbial pathogens), and abiotic (e.g., environmental and soil conditions) factors [13,14].

Lupin QAs constitute a natural defensive chemical barrier facing biotic pressures [15]. Thus, despite their well-known acute anticholinergic toxicity, they can be explored as alternatives (or even compound templates) against pests and pathogens. In this regard, some QAs isolated from Lupinus, such as sparteine, lupanine, and lupinine, have been used to control intestinal ectoparasites in cattle [16], and farmers occasionally use a QArich infusion from seeds for pest control in plants [17]. In addition, QA-rich Lupinus extracts (QREs) have shown antimicrobial activity against different microorganisms. For instance, the extracts of L. mutabilis seeds have inhibited $95 \%$ of the growth of Staphylococcus aureus [18], while Candida fungi have shown $>60 \%$ inhibition in the presence of QREs of $L$. arboreus leaves [19], L. albescens [20], L. angustifolius [21], and L. densiflorus [22]. The seedderived QREs from L. exaltatus and L. mexicanus have also been reported, showing inhibition $>72 \%$ against Sclerotium rolfsii, Alternaria solani, Rhizoctonia solani, and F. oxysporum [23]. In the case of phytopathogens of the genus Fusarium, F. oxysporum and F. verticillioides showed susceptibility to QREs of L. albescens, with $\mathrm{IC}_{50}$ values $<30 \mu \mathrm{g} / \mathrm{mL}$ [20].

The current phytosanitary problems associated with the attack of F. oxysporum remain to be solved. Crops infected with this phytopathogen experience fusariosis, a plant disease that causes damage from leaf chlorosis to vascular necrosis [24]. These adverse effects produce significant economic losses in the agricultural sector [25], specifically in crops such as cape gooseberrys [26], bananas [27], carnations [28], lulos, and strawberries [29]. Fungicides such as dithane-M45, manzate 200WP, fitoraz, rovral-Flo, folicur EW, stroby SC, azoxystrobin, benomyl, carbendazim, and fludioxonil are currently used for the management of fusariosis $[30,31]$. However, the excessive use of these products led to adverse effects such as the production of resistant strains that seriously affect some important crops, such as bananas [32].

Similarly, other problems related to the inappropriate use of fungicides have affected the environment, microbiota, and soil fertility due to non-biodegradable, persistent, and bioaccumulative chemicals [33,34]. Therefore, there is a continual need to search for competent alternatives to synthetic pesticides to control this phytopathogen that can eventually be incorporated into rigorously controlled integrated pest management (IPM) programs. The exploration to find antifungals might be advantageous from plant sources with favorable propagation, such as species of the genus Lupinus. In addition, since the particular production mainly contributes to the structural diversity in Lupinus leaves and considering that QAs are biologically active specialized metabolites and plant defense products [2], naturally-supplied QA mixtures could be examined as a promising approach for exerting concomitant effects on F. oxysporum.

Therefore, the present study evaluated the antifungal activity against $F$. oxysporum of QREs obtained from eight Lupinus species cultivated under greenhouse conditions. Thus, the quinolizidine variations in the test Lupinus species were employed to recognize patterns and identify the most active QAs and their mixtures as plausible antifungals from foliar materials of cultivated lupin plants.

\section{Results and Discussion}

\subsection{Characteristics of Propagated Plants}

The leaf collection stage of native species was defined when plants showed their first flower buds and reached ca. $50 \mathrm{~cm}$ in height. Only average heights around $20 \mathrm{~cm}$ were reached in exotic species, except $L$. albus specimens that exceeded $50 \mathrm{~cm}$ in height. In the case of L. polyphyllus and L. perennis, no floral buds were observed. The flowering could be affected by the unusual temperature conditions of the greenhouse (mainly cold periods 
and irradiation) for these exotic plants, since vernalization and photoperiods have been described to affect the flowering periods of some lupins seriously, e.g., L. luteus [35].

Additionally, high temperatures can alter the phenological stages of Lupinus [36] in such a way that lower production of flowers and seeds is observed, while in more extreme cases, the flowering stage is not reached [37]. However, exotic lupin plants grew under the employed propagation conditions, indicating good acclimatization of Lupinus species to such a growing environment, which is beneficial when mass cultivating for harvesting purposes. Thus, all lupin plants reached satisfactory growth to collect enough leaf biomass for the subsequent chemical analysis.

\subsection{Chemical Analysis}

The young leaves were collected once the lupin plants reached physiological maturity (i.e., $70 \pm 19$ days after transplantation). Hence, QREs from fresh leaves $(5 \mathrm{~g})$ of the eight Lupinus species were prepared to afford the yields shown in Table S1 (supplementary material), following an acid-base extraction method. The highest yields were achieved for L. bogotensis, L. mirabilis, and L. mutabilis (yields > 5\%). Contrarily, the exotic species yielded lower extract amounts, but the best yields between them resulted for L. polyphyllus, L. perennis, and L. albus (yields $>4 \%$ ), while L. argenteus and L. arboreus showed the lowest yields $(<3 \%)$. The yield differences of native lupine plants compared to exotic ones can be explained by biomass and specialized metabolite variations due to those intrinsic (genetic) factors favored by extrinsic (environmental) factors related to the propagation conditions managed in the present study [38].

GC-MS analysis subsequently recorded the QA composition of these QREs obtained from the eight Lupinus plants. With the diagnostic analysis of the mass spectra combined with the retention indices compared to the available information in literature, QAs 1-13, which are listed in Table 1 and whose structures are shown in Figure S1, were identified.

Table 1. Identified quinolizidines (1-13) in eight lupin species propagated under greenhouse conditions.

\begin{tabular}{|c|c|c|c|c|c|}
\hline$\#^{\mathbf{a}}$ & $\mathrm{Rt}^{\mathrm{b}}$ (min) & Name & $\mathrm{RI}^{\mathrm{c}}$ & $\mathrm{RI}^{\mathrm{d}}$ & Reference $^{d}$ \\
\hline 1 & 20.5 & sparteine & 1785 & 1805 & [39] \\
\hline 2 & 21.6 & 11,12-dehydrosparteine & 1841 & 1841 & [40] \\
\hline 3 & 24.4 & $N$-methylcytisine & 1918 & 1924 & [41] \\
\hline 4 & 25.8 & angustifoline & 2079 & 2073 & [39] \\
\hline 5 & 26.3 & 5,6-dehydrolupanine & 2104 & 2092 & [40] \\
\hline 6 & 27.1 & $\alpha$-isolupanine & 2107 & 2123 & [39] \\
\hline 7 & 27.7 & lupanine & 2170 & 2146 & [42] \\
\hline 8 & 29.0 & nuttalline & 2338 & 2348 & [18] \\
\hline 9 & 30.9 & matrine & 2366 & 2365 & [43] \\
\hline 10 & 31.1 & anagyrine & 2390 & 2377 & [40] \\
\hline 11 & 31.4 & $13 \alpha$-hydroxylupanine & 2405 & 2400 & [39] \\
\hline 12 & 35.7 & multiflorine & 2440 & 2469 & [18] \\
\hline 13 & 36.0 & 17-oxolupanine & 2482 & 2473 & [18] \\
\hline
\end{tabular}

${ }^{a}$ Compound numbers according to the chromatographic elution presented in Figure $1 ;{ }^{\mathrm{b}} \mathrm{Rt}=$ retention time $(\mathrm{min})$ ${ }^{\mathrm{c}}$ Calculated retention index (RI) according to the Equation (S1); and ${ }^{\mathrm{d}}$ Reported RI according to the respective reference.

The identified QAs have already been reported as phytocomponents in Lupinus species. Some of them are commonly found as the most abundant QAs, being part of certain mixtures at differentiated proportions between species or even due to the effects caused by biotic and abiotic factors [13,44]. Qualitative and quantitative comparisons were made between the eight lupin species propagated under the same conditions in the present study. Accordingly, the stacked chromatographic profiles are shown in Figure 1 and the measured contents per QA of these test plants, expressed as $\mathrm{mg} / \mathrm{g}$ fresh leaves (fl), are presented in Table 2. Some compound signals (i.e., 6) are not entirely visualized in Figure 1 due to the relative abundance, despite being quantified according to the limit of quantification (see 
Section 3.3), since the most abundant compounds per GC-MS chromatogram reduced the visible intensity of those signals related to the minor compounds.

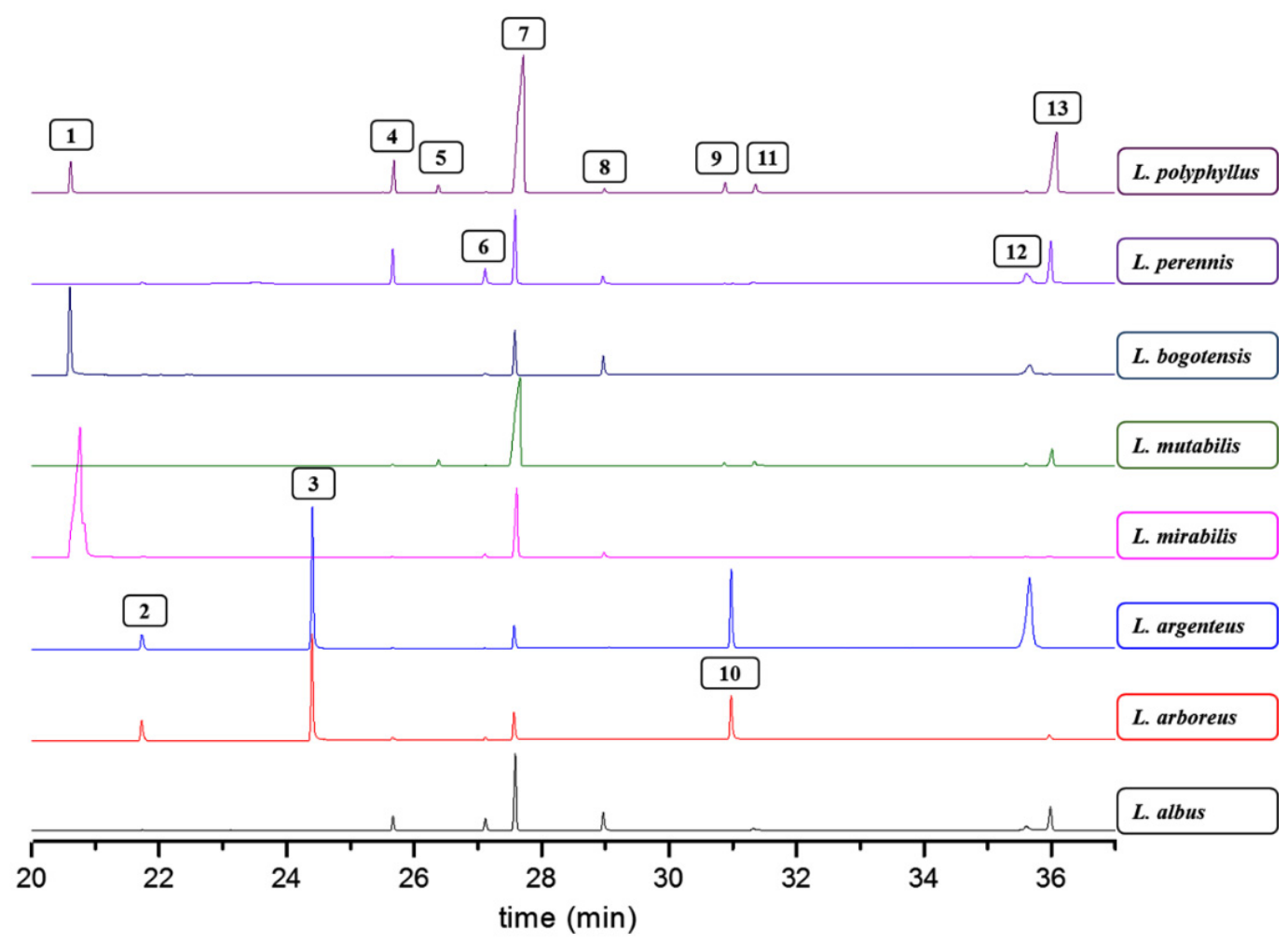

Figure 1. Stacked GC-MS chromatograms of quinolizidine-rich extracts (QREs) were obtained from the eight species of Lupinus. The box-enclosed numbers represent each identified quinolizidine listed in Table 1.

The QRE profiles changed in the presence and abundance of QAs, whose contents varied within a $0.031-32.8 \mathrm{mg} / \mathrm{g}$ fl range. Some common QAs were found in all test species, as in the case of 6 and 7, with contents between $0.046-3.12$ and $5.62-25.7 \mathrm{mg} / \mathrm{g} \mathrm{fl}$, respectively. In contrast, other QAs were not commonly found in the sample set, such as 9 $(0.043-3.54 \mathrm{mg} / \mathrm{g} \mathrm{fl})$, as most reported in the genus Sophora [43]. In the case of the species $L$. argenteus and L. arboreus, QAs containing the 2-pyridone moiety, such as $\mathbf{3}$ and $\mathbf{1 0}$, were the most common compounds, comprising contents between 4.61 and $6.08 \mathrm{mg} / \mathrm{g}$ fl. A previous study reported that $L$. argenteus ecotypes exhibited the presence of seventeen QAs, including lupanine derivatives such as 5,6-dehydrolupanine, $\alpha$-isolupanine, 11,12-dehydrolupanine, 3-hydroxylupanine, and thermopsine [45], but the abundance and presence of lupanine derivatives were found to be different in L. argenteus under study. QAs 7 and $\mathbf{1 1}$ have been previously reported for $L$. arboreus, but $\mathbf{1 1}$ mainly accumulates in L. arboreus seeds; therefore, it was not detected in this study [46]. In the case of L. albus, QAs 4, 7, 8, and 12 were identified and quantified (between 0.91 and $13.8 \mathrm{mg} / \mathrm{g} \mathrm{fl}$ ). However, the presence of albine was reported in previous studies [47], but it was not detected in the L. albus-derived extracts under investigation. Finally, in native species such as L. mutabilis and L. bogotensis, compounds $\mathbf{1}, \mathbf{2}, \mathbf{4 - 8}$, and 12 have previously been reported [8,48], agreeing with the results of the present study involving the highly-varied contents of such QAs (between 0.033 and $32.8 \mathrm{mg} / \mathrm{g} \mathrm{fl}$ ). The presence of $\mathbf{1}, \mathbf{7}, \mathbf{9}$, and $\mathbf{1 0}$ has been generally reported in the genera Lupinus, Sophora, and Genista species. 
Table 2. Contents of quinolizidines 1-13 in leaves of eight Lupinus species.

\begin{tabular}{|c|c|c|c|c|c|c|c|}
\hline \multirow{2}{*}{ Plants } & \multicolumn{7}{|c|}{ QA Content (mg LE/g FL) ${ }^{a}$} \\
\hline & 1 & 2 & 3 & 4 & 5 & 6 & 7 \\
\hline L.po. & $1.43 \pm 0.12^{\mathrm{C}}$ & n.d. & n.d. & $5.39 \pm 0.18^{\mathrm{A}}$ & $0.391 \pm 0.008^{\mathrm{B}}$ & $0.169 \pm 0.009^{\mathrm{E}}$ & $17.1 \pm 0.9^{\mathrm{C}}$ \\
\hline L.pe. & n.d. & $0.031 \pm 0.001^{\mathrm{D}}$ & n.d. & $3.12 \pm 0.12^{\mathrm{B}}$ & n.d. & $1.607 \pm 0.032^{\mathrm{B}}$ & $20.0 \pm 0.2^{\mathrm{B}}$ \\
\hline L.b. & $22.4 \pm 0.7^{\mathrm{B}}$ & $0.033 \pm 0.002^{\mathrm{D}}$ & n.d. & n.d. & n.d. & $0.083 \pm 0.002^{\mathrm{F}}$ & $19.3 \pm 0.8^{\mathrm{B}}$ \\
\hline L.mu. & n.d. & n.d. & n.d. & $0.87 \pm 0.09^{\mathrm{C}}$ & $1.42 \pm 0.16^{\mathrm{A}}$ & $0.452 \pm 0.009^{\mathrm{C}}$ & $25.7 \pm 0.6^{\mathrm{A}}$ \\
\hline L.mi. & $32.8 \pm 0.6^{\mathrm{A}}$ & $0.102 \pm 0.004^{C}$ & n.d. & $0.102 \pm 0.008^{\mathrm{D}}$ & n.d. & $0.151 \pm 0.006^{\mathrm{E}}$ & $20.1 \pm 0.31^{\text {B }}$ \\
\hline L.arg. & n.d. & $1.38 \pm 0.19^{\mathrm{B}}$ & $4.98 \pm 0.19^{\mathrm{B}}$ & $0.051 \pm 0.003^{\mathrm{E}}$ & n.d. & $0.201 \pm 0.016^{\mathrm{D}}$ & $5.62 \pm 0.14^{\mathrm{F}}$ \\
\hline L.arb & n.d. & $2.07 \pm 0.16^{\mathrm{A}}$ & $5.69 \pm 0.21^{\mathrm{A}}$ & $0.046 \pm 0.002^{\mathrm{E}}$ & n.d. & $0.046 \pm 0.003^{\mathrm{G}}$ & $6.56 \pm 0.20^{\mathrm{G}}$ \\
\hline L.al. & n.d. & n.d. & n.d. & $3.35 \pm 0.14^{\mathrm{B}}$ & n.d. & $3.12 \pm 0.06^{\mathrm{A}}$ & $13.8 \pm 0.9^{\mathrm{D}}$ \\
\hline \multirow{2}{*}{ Plants } & \multicolumn{6}{|c|}{ QA Content (mg LE/g FL) ${ }^{a}$} & \\
\hline & 8 & 9 & 10 & 11 & 12 & 13 & \\
\hline L.po. & $1.08 \pm 0.09^{C}$ & $3.54 \pm 0.08^{\mathrm{A}}$ & n.d. & $2.62 \pm 0.09 \mathrm{~A}$ & $0.328 \pm 0.013^{\mathrm{C}}$ & $9.40 \pm 0.75^{\mathrm{A}}$ & \\
\hline L.pe. & $0.735 \pm 0.059^{\mathrm{D}}$ & $0.043 \pm 0.003^{C}$ & $0.048 \pm 0.001^{C}$ & $0.068 \pm 0.002^{\mathrm{D}}$ & $0.154 \pm 0.005^{\mathrm{E}}$ & $4.09 \pm 0.11^{\mathrm{C}}$ & \\
\hline L.b. & $5.41 \pm 0.16^{\mathrm{B}}$ & n.d. & n.d. & n.d. & $0.209 \pm 0.017^{\mathrm{D}}$ & $0.051 \pm 0.005^{\mathrm{F}}$ & \\
\hline L.mu. & n.d. & $0.729 \pm 0.008^{B}$ & n.d. & $0.727 \pm 0.011^{\mathrm{B}}$ & $0.812 \pm 0.012^{\mathrm{B}}$ & $4.98 \pm 0.23^{\mathrm{B}}$ & \\
\hline L.mi. & $0.176 \pm 0.011^{\mathrm{E}}$ & n.d. & n.d. & n.d. & $0.045 \pm 0.002^{\mathrm{F}}$ & $0.063 \pm 0.006^{\mathrm{F}}$ & \\
\hline L.arg. & n.d. & n.d. & $6.08 \pm 0.07^{\mathrm{A}}$ & n.d. & $4.88 \pm 0.34^{\mathrm{A}}$ & n.d. & \\
\hline L.arb & n.d. & n.d. & $4.61 \pm 0.13^{\mathrm{B}}$ & n.d. & n.d. & $0.104 \pm 0.008^{\mathrm{E}}$ & \\
\hline L.al. & $6.15 \pm 0.08^{\mathrm{A}}$ & n.d. & n.d. & $0.377 \pm 0.011^{\mathrm{C}}$ & $0.910 \pm 0.017^{\mathrm{B}}$ & $4.97 \pm 0.21^{\mathrm{B}}$ & \\
\hline
\end{tabular}

a Contents expressed as mg of lupanine equivalents per gram of fresh leaves (mg LE/g FL); the presented values comprise means \pm standard deviation $(n=10)$. L.po. $=$ L. polyphyllus, L.pe. $=$ L. perennis, L.b. $=$ L. bogotensis, L.mu $=$ L. mutabilis, L.mi. $=$ L. mirabilis, L.arg $=$ L. argenteus, L.arb. $=$ L. arboreus, L.al. $=$ L. albus. Different uppercase capital letters indicate statistically significant differences according to the post hoc Tukey test $(p<0.05)$. n.d. $=$ not detected.

All Lupinus species were characterized by the high production and accumulation of lupanine (7), exploited as a useful chemotaxonomic marker to recognize Lupinus species [2]. In native species, close lupanine contents were found, although $L$. mutabilis exhibited the highest and significantly different content. In the case of exotic species, some differences were found and could be gathered into two groups as follows: In the first group, L. argenteus and $L$. arboreus were characterized by the low content of $7(<7 \mathrm{mg} / \mathrm{g} \mathrm{fl})$ and the presence of QAs 3 and 10, which are not commonly reported in Lupinus species but highly occurred in Genista species $[49,50]$. In the second group, the species L. polyphyllus, L. albus, and L. perennis showed important contents of 7 but the highest abundance of $4(5.39,3.35$, and $3.12 \mathrm{mg} / \mathrm{g} \mathrm{fl}$, respectively) and other characteristic compounds of these species such as 8 and 11 (within content ranges of $0.735-6.15$ and $0.068-2.62 \mathrm{mg} / \mathrm{g}$ fl, respectively).

\subsection{Direct Bioautography Assay}

Bioautography allowed qualitatively observing the sensitivity of the phytopathogen spores to the test QREs (Figure 2A). In this way, the negative control (D3, distilled water) exhibited a completely dark surface, representing the phytopathogen growth in that square [51]. In contrast, positive controls Dithane and Rovral (squares B1 and B3) revealed clear zones, indicating no fungal growth due to the inhibition of spore germination [52]. Similarly, QRE-based treatments (squares A1-A3, B2, C1-C3, and D1-D2) produced similar inhibition halos to positive controls. Thus, although some distinctive intensities were evidenced, these results qualitatively indicated that all test extracts exhibit antifungal activity on F. oxysporum spores. 
(A)

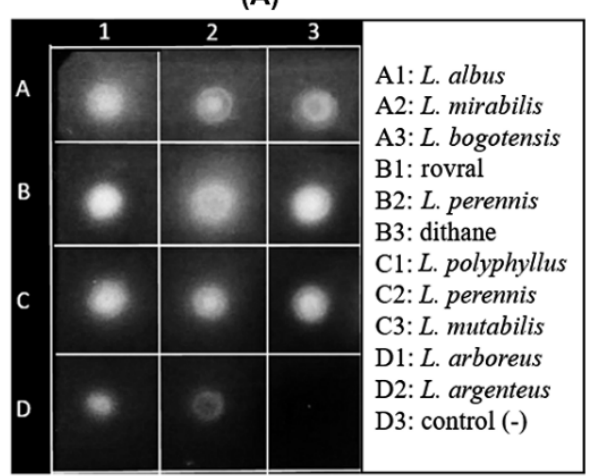

(B)

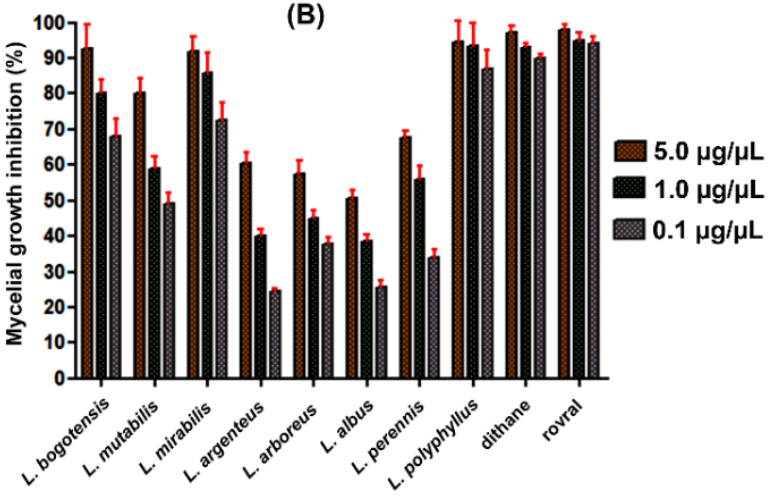

Figure 2. Antifungal activity against F. oxysporum QREs from eight lupin species. (A) Bioautography results using $50 \mu \mathrm{g}$ of QREs; (B) Mycelial growth inhibition percentages of eight QREs at three concentrations.

\subsection{Mycelial Growth Inhibition Assay}

The antifungal activity evaluation of the Lupinus-derived QREs against F. oxysporum was quantitatively extended by assessing the mycelium growth inhibition through the amended-medium (poisoned food) technique. Thus, QREs were evaluated at three doses (i.e., 5.0, 1.0, and $0.1 \mu \mathrm{g} / \mu \mathrm{L}$ ) and, subsequently, the respective inhibition percentages were measured, obtaining values $>50 \%$ at the maximum concentration (Figure $2 \mathrm{~B}$ ). The $L$. polyphyllus-derived QRE showed the best antifungal activity at the three test concentrations (inhibition $>85 \%$ ), and such inhibitions were very similar to those of positive controls. However, the observed antifungal activity variations depended on the treatment and QAs composition involved significant differences $(p<0.05)$. Thus, using the post hoc Tukey test, the statistically significant differences based on variations in composition and concentration were obtained. Consequently, twenty different mean groups were achieved (Figure S2, supplementary material). The first significantly different groups (i.e., A-F) were related to the best inhibition values $(>80 \%)$, comprising positive controls and extracts from $L$. polyphyllus, L. bogotensis, L. mirabilis, and L. mutabilis at the highest test concentrations (1 and $5 \mu \mathrm{g} / \mu \mathrm{L})$. The other groups represented a lesser inhibition $(<75 \%)$ showed by the other extracts, mainly dependent on the concentration of each QRE. The measured inhibition values agree with the values reported for QREs obtained from L. exaltatus [53]. L. argenteus, L. arboreus, L. albus, and L. perennis exhibited the lowest inhibitory activity on mycelial growth (inhibition between 20 and $60 \%$, depending on the concentration). However, $L$. albus and L. perennis exhibited clear zones of inhibition in the bioautography, even similar to other QREs treatments (Figure 2A), suggesting a plausible selective effect depending on the fungal structure (spore $>$ mycelium), which might be clarified in further studies.

The test QREs showed differences in their chemical composition and antifungal activity against $F$. oxysporum. In general, the eight lupin species showed the best antifungal activity at the maximum test concentration $(5 \mu \mathrm{g} / \mu \mathrm{L})$, comprising inhibition percentages between $50-95 \%$. As mentioned above, the most active QREs were those obtained from $L$. polyphyllus and L. bogotensis. These QREs showed dose-dependent differences, as shown in Figure 3A. For example, $\mathbf{C 1}$ (treatment at $5 \mu \mathrm{g} / \mu \mathrm{L}$ ) highly inhibited the mycelial growth of the phytopathogen (inhibition $>95 \%$ ), while $\mathbf{C} 2$ (treatment at $1 \mu \mathrm{g} / \mu \mathrm{L}$ ) showed lower mycelial growth (inhibition $>80 \%$ ). In the case of $\mathbf{C} 3$ (treatment at $0.1 \mu \mathrm{g} / \mu \mathrm{L}$ ), moderate mycelial growth was observed (inhibition $>70 \%$ ). On the other hand, the intermediate doses (C2) of the QREs obtained from L. polyphyllus, L. bogotensis, and L. mirabilis showed the best results (inhibition $>80 \%$ ), while a significant inhibitory reduction was found for the other five species (inhibition $<60 \%$ ). Finally, the least active concentration was C3. At this dose, L. polyphyllus, L. bogotensis, and L. mirabilis afforded the best results (inhibition > $70 \%$ ), while QREs from the other species were found to be below $60 \%$. In this sense, these 
results suggest that the optimal threshold for an effective dose to inhibit the growth of $F$. oxysporum mycelium by these QREs is $5 \mu \mathrm{g} / \mu \mathrm{L}(0.5 \% w / v)$.

(A)

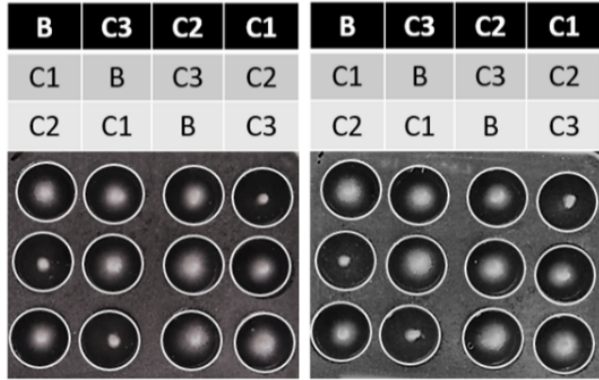

(B)

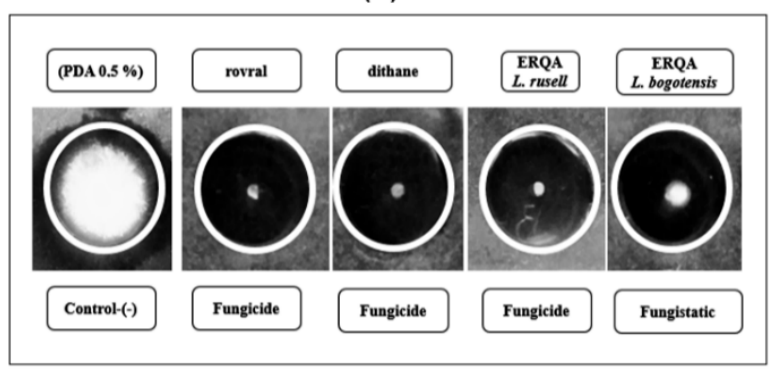

Figure 3. (A) Antifungal activity (mycelial growth inhibition) evaluated for the most-active QREs from L. polyphyllus (left) and L. bogotensis (right) against F. oxysporum. (B) (PDA 0.5\%), C1 (5 $\mu \mathrm{g} / \mu \mathrm{L})$, C2 $(1 \mu \mathrm{g} / \mu \mathrm{L})$, and C3 $(0.1 \mu \mathrm{g} / \mu \mathrm{L})$. (B) Fungicide vs. Fungistatic of the most-active QREs of $L$. polyphyllus and L. bogotensis.

Once the mycelial growth inhibition assay time elapsed, a subsequent test was performed to classify the extracts as fungicidal or fungistatic. This test was accomplished by further monitoring the fungal growth in fresh PDA after completion of QRE treatment at $5 \mu \mathrm{g} / \mu \mathrm{L}$. This test suggested that seven lupin-derived extracts were fungistatic (Figure 3B). In contrast, there was no mycelium growth for the L. polyphyllus-derived QRE, indicating a fungicidal behavior. In addition, there are some studies related to QAs and bisquinolizidine alkaloids, such as spirocytisine, 3,5-dibromocytisine, bromo- $\mathrm{N}$-boccytisine, $\mathrm{N}$-boccytisine, 3-bromobenzyl cytisine, 4-bromo-benzylcytisine, 3-iodobenzylcytisine, and 4-iodobenzylcytisine, evaluated against Aspergillus niger van Tieghem ATCC 6275, and all of them showed fungistatic activity [54].

The detailed scrutiny of the chemical and antifungal activity data integration of test QREs led us to recognize meaningful patterns. Initially, intuitive visualization of the comparison of autoscaled QA contents revealed plausible contributions by some QAs to the antifungal activity (Figure 4A). In this regard, QREs containing particular combinations of specific QAs were generally the most active extracts. Thus, the most active QRE, derived

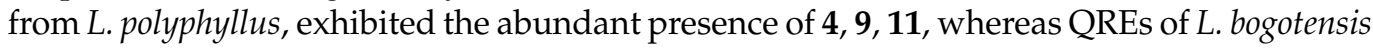
(the second most active extract against $F$. oxysporum) contained $\mathbf{1}$ and $\mathbf{8}$ in high abundance and L. mirabilis exhibited the highest content of $\mathbf{1}$. Remarkably, compound $\mathbf{9}$ was only detected in the most active QREs from L. mutabilis and L. polyphyllus, whose interesting inhibitory properties on conidia germination of F. oxysporum, Sphaeropsis spainea, Valsa pini $\left(\mathrm{IC}_{50}<600 \mu \mathrm{g} / \mathrm{mL}\right)$ were previously evaluated [55]. The other lupin species that did not contain 1, 4, 9, and/or 11, showed the lowest activity, with inhibition $<70 \%$ in the three treatments. This in-depth exploration was extended by an unpaired fold-change (FC) analysis performed on QA content data of the test QREs, involving two antifungal activity-related datasets, i.e., more active QREs with $>80 \%$ inhibition and less active QREs with $<75 \%$ inhibition. The resulting plot (Figure $4 \mathrm{~B}$ ) showed the important QAs selected by this FC analysis (threshold =2), and the red and blue dots represent QAs above and below such a threshold, respectively. This logarithmic relative change between the two activityrelated datasets can be statistically interpreted as a positive and negative contribution to the antifungal activity by a QA due to its particular presence in a more active or less active QRE, respectively. Thus, QAs 2, 3, 6, 10, and 12 contributed negatively to the antifungal activity, whereas 5, 7, and 8 exhibited no contribution since the FC threshold was not exceeded. In contrast, the significance of $1,4,9,11$, and 13 was statistically evidenced by their positive contribution to the antifungal activity. They can be considered essential constituents of a bioactive QRE and a plausible, promising mixture against F. oxysporum. The particular combination of QAs in the L. polyphyllus-derived QRE might rationalize its 
observed fungicidal activity. In this regard, such a QA-based combination could be due to the growing behavior at the test greenhouse conditions since this introduced plant did not reach the flowering stage. This fact may be a critical factor influencing the composition and, consequently, the antifungal activity of this most active lupin plant.

(A)

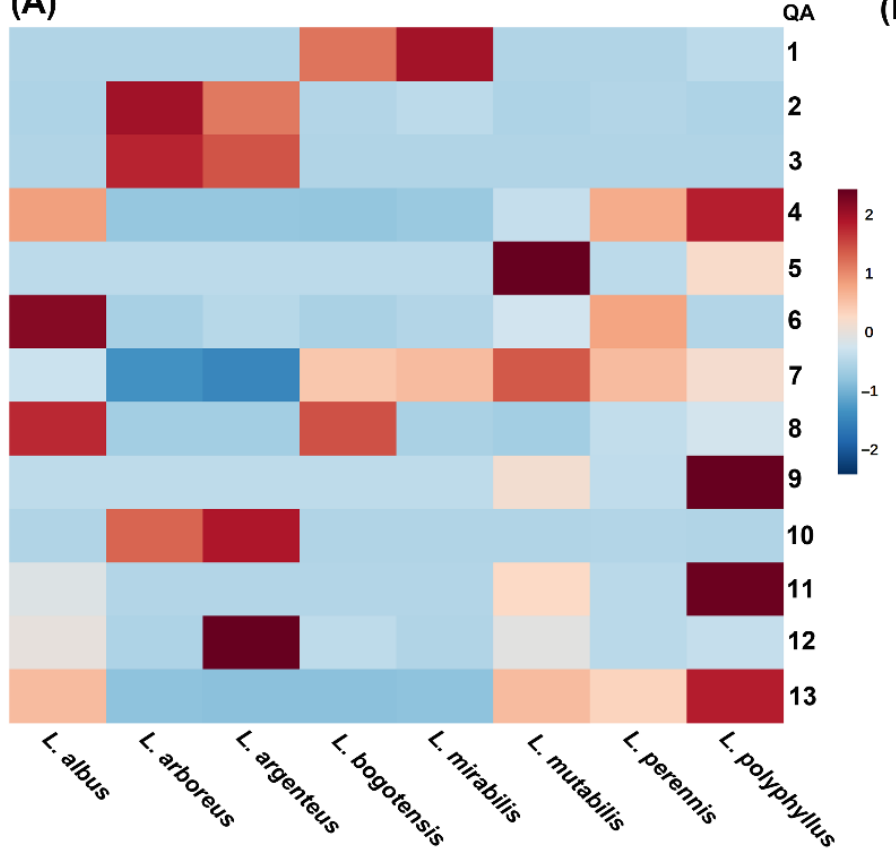

(B)

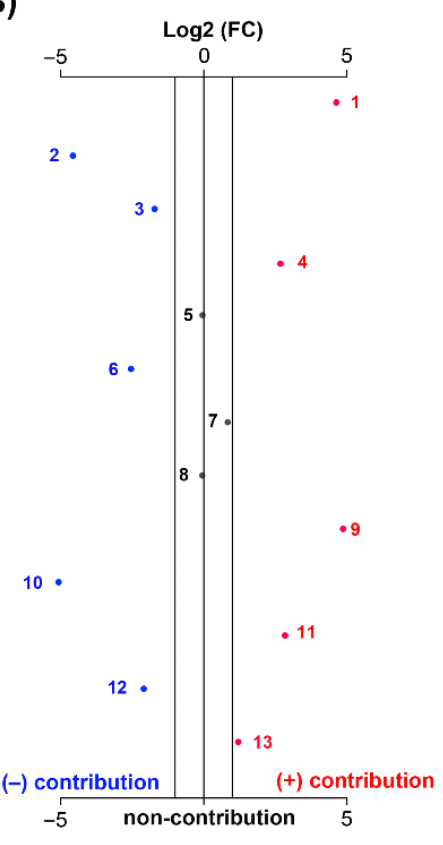

Figure 4. Comparison of QA contents (mg/g fresh leaves) among QREs obtained from leaves of eight lupin species. (A) Heatmap visualization of the normalized content distribution (unit of variance scaling) of QAs 1-13 from test lupins. Autoscaled QA contents are related to the color scale: $2=$ high content; -2 = low content. (B) Unpaired fold-change (FC) analysis plot for selecting important QAs with threshold 2, by integrating the chemical (QA contents) and biological (mycelial growth inhibition) data. Antifungal activity was used as a categorical variable, subdividing the antifungal activity of QREs into two datasets: more active ( $>80 \%$ inhibition) and less active ( $<75 \%$ inhibition), according to the Tukey test, to supervise the QA selection. According to the antifungal activity, positive and negative contributions to the FC-based QA selection are depicted as red and blue numbers and dots.

On the other hand, this integrated examination also suggests that very high contents of 7 are not a determinant for antifungal activity against F. oxysporum as the five selected QAs. This observation agrees with a previous study on a QRE obtained from L. exaltatus seeds. Such an extract did not show antifungal activity against $F$. oxysporum and its QA composition was based on a high relative abundance of $7(53.2 \%)$, along with other derivatives and aphylline and sparteine in lower relative abundance $(<10 \%)$ [53]. Therefore, a QRE whose composition mainly contains compound 7 and some of its analogs, such as $L$. albus-derived QRE, cannot be considered effective in inhibiting the F. oxysporum growth $(<50 \%)$. A similar result was found in a previous study with a QRE obtained from $L$. mexicanus seeds, whose practically insignificant antifungal activity against $F$. oxysporum was observed. The test extract was mainly composed of high contents of 7 (content $=21.2$ $\mathrm{mg} / \mathrm{g}$, relative abundance $=76.2 \%)$, along with other QAs with lower content $(<3 \mathrm{mg} / \mathrm{g})$ and relative abundance $(<10 \%)$ [56]. Finally, the activity of QREs having good contents of 3 and $10(4.61-6.08 \mathrm{mg} / \mathrm{g} \mathrm{fl})$ was found to be moderate to low. In this regard, other QAs containing the 2-pyridone moiety (e.g., cytisine) have exhibited bactericidal and antifungal activities [54,57]. However, the antifungal activity of $\mathbf{3}$ and $\mathbf{1 0}$ could not be statistically recognized, possibly by low inhibition by structural reasons that should be deepened in further structure-activity relationship studies. 


\subsection{Variation in the $Q A$ Profiles of L. polyphyllus Induced by Pruning Events}

L. polyphyllus "Russell" was an exotic lupin species that quickly propagated under these greenhouse conditions, although a flowering stage was not reached. However, the leaf production was abundant, so periodically (every two weeks), the young leaves were pruned to obtain $5 \mathrm{~g}$ of fresh plant material. This pruning process was performed twelve times, and consequently, twelve QREs were obtained which were further analyzed by GC-MS. This pruning-based exploration on this most active QRE-producing lupin plant helped refine the chemical and biological data integration to select bioactive QAs through inherent variations.

The resulting chromatograms are shown in Figure 5. The QREs of L. polyphyllus were qualitatively and quantitatively compared, and some changes associated with the presence and abundance of detected alkaloids in each resulting QRE were observed. Hence, ten QAs were detected and quantified (contents between 0.003 and $1.86 \mathrm{mg} / \mathrm{g} \mathrm{fl}$ ), along with pruning events (PEs) (Table 3).

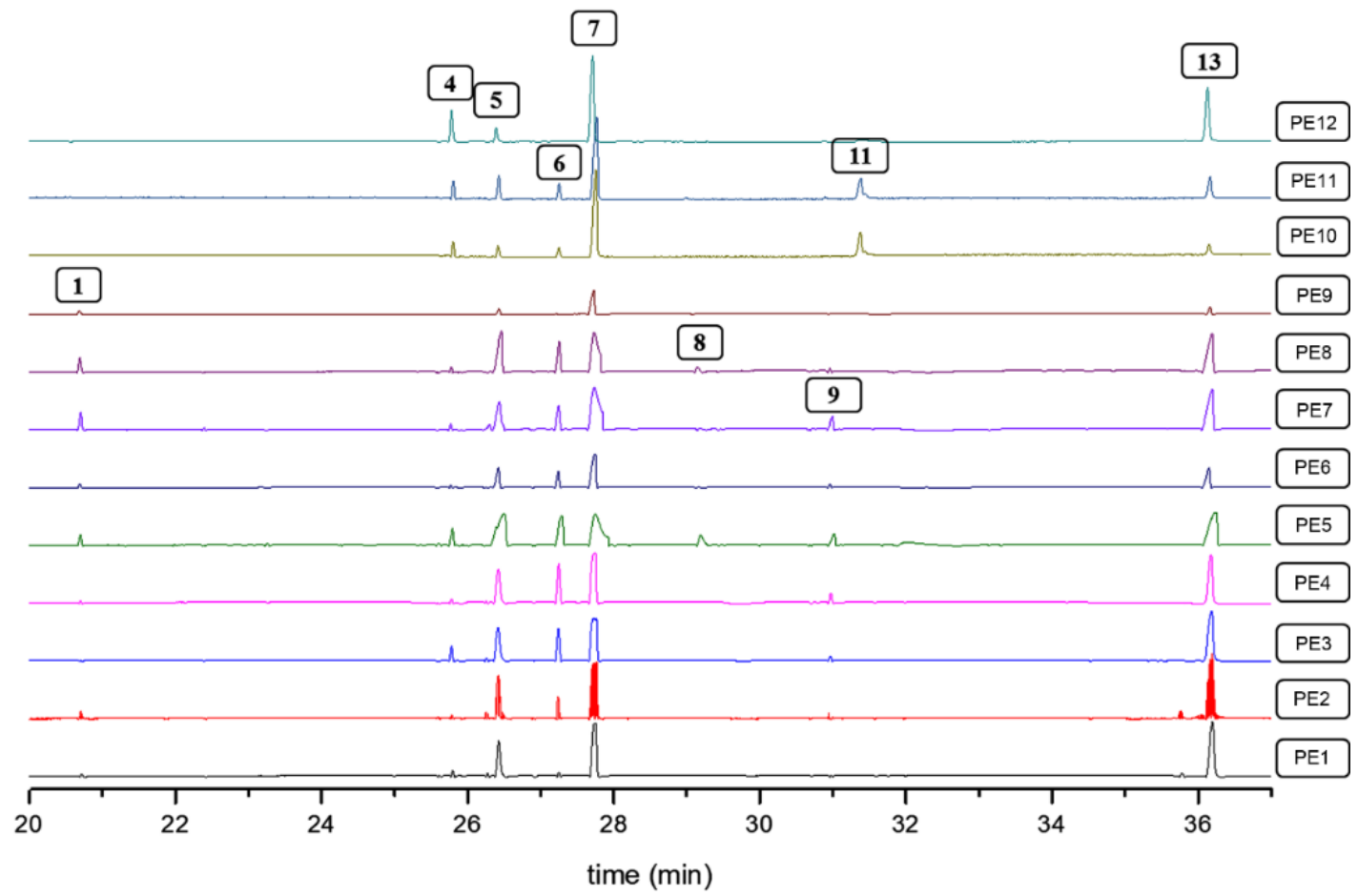

Figure 5. Stacked GC-MS chromatograms of quinolizidine-rich extract (QRE), obtained after pruning events (PE1-12) on L. polyphyllus. The box-enclosed numbers represent each identified quinolizidines, listed in Table $1 . \mathrm{PE}=$ pruning event.

In general, all QREs contained 4, 5, 7, 13, while 1, 6, 8, 9, 11, 12 were evidenced in selected PEs. Notably, compound 1 showed content variations for each PE $(0.009$ $0.375 \mathrm{mg} / \mathrm{g}$ fl), with PE7-8 showing significantly higher abundance. Compound $\mathbf{1}$ has been previously reported in Lupinus genotypes, and its antimicrobial history against $K$. pneumoniae and P. aeruginosa has been highlighted [18]. A content increase for 9 was observed from PE3-7, but no longer detected from PE9. This compound is vital due to its antimicrobial [55,58], antiparasitic [59], cytotoxic [60], anticarcinogenic [61], antiviral, [62] and antimalarial properties $[63,64]$. 
Table 3. Contents of quinolizidines detected in extracts from L. polyphyllus leaves after pruning events (p1-p12).

\begin{tabular}{|c|c|c|c|c|c|}
\hline \multirow{2}{*}{$\mathrm{PE}^{\mathrm{a}}$} & \multicolumn{5}{|c|}{ QA Content (mg LE/g FL) ${ }^{b}$} \\
\hline & 1 & 4 & 5 & 6 & 7 \\
\hline PE1 & $0.011 \pm 0.001^{\mathrm{F}}$ & $0.123 \pm 0.011^{G}$ & $1.73 \pm 0.09^{\mathrm{G}}$ & $1.07 \pm 0.08^{\mathrm{E}}$ & $11.3 \pm 0.4^{\mathrm{E}}$ \\
\hline PE2 & $0.009 \pm 0.001^{\mathrm{F}}$ & $0.115 \pm 0.003^{G}$ & $2.77 \pm 0.22 \mathrm{EF}$ & $1.12 \pm 0.09^{\mathrm{E}}$ & $14.8 \pm 0.4^{C}$ \\
\hline PE3 & $0.014 \pm 0.001^{\mathrm{F}}$ & $0.130 \pm 0.009$ FG & $1.42 \pm 0.11^{\mathrm{G}}$ & $1.70 \pm 0.12^{C}$ & $12.7 \pm 0.3^{\mathrm{D}}$ \\
\hline PE4 & $0.016 \pm 0.001^{\mathrm{E}}$ & $0.269 \pm 0.011^{\mathrm{E}}$ & $3.57 \pm 0.14^{\mathrm{D}}$ & $0.90 \pm 0.06^{\mathrm{F}}$ & $13.7 \pm 0.7^{\mathrm{CD}}$ \\
\hline PE5 & $0.118 \pm 0.006^{\mathrm{D}}$ & $0.341 \pm 0.017^{\mathrm{D}}$ & $5.32 \pm 0.08^{\mathrm{B}}$ & $1.39 \pm 0.04^{\mathrm{D}}$ & $18.6 \pm 0.6^{\mathrm{A}}$ \\
\hline PE6 & $0.184 \pm 0.015^{\mathrm{C}}$ & $0.094 \pm 0.003^{\mathrm{G}}$ & $8.72 \pm 0.09^{\mathrm{A}}$ & $3.36 \pm 0.22^{\mathrm{B}}$ & $14.8 \pm 0.8^{C}$ \\
\hline PE7 & $0.375 \pm 0.004^{\mathrm{A}}$ & $0.137 \pm 0.001^{\mathrm{F}}$ & $8.93 \pm 0.17^{\mathrm{A}}$ & $5.15 \pm 0.10^{\mathrm{A}}$ & $16.9 \pm 0.7^{\mathrm{B}}$ \\
\hline PE8 & $0.282 \pm 0.006^{\mathrm{B}}$ & $0.139 \pm 0.003^{\mathrm{F}}$ & $8.52 \pm 0.15^{\mathrm{A}}$ & $3.57 \pm 0.21^{\mathrm{B}}$ & $15.5 \pm 0.5^{\mathrm{C}}$ \\
\hline PE9 & $0.131 \pm 0.007^{\mathrm{D}}$ & $0.003 \pm 0.001^{\mathrm{H}}$ & $5.04 \pm 0.21^{\mathrm{B}}$ & $0.009 \pm 0.001^{\mathrm{G}}$ & $13.4 \pm 0.8^{\mathrm{CD}}$ \\
\hline PE10 & tr. & $1.602 \pm 0.128^{\mathrm{B}}$ & $4.49 \pm 0.14^{\mathrm{C}}$ & $1.12 \pm 0.05^{\mathrm{E}}$ & $11.7 \pm 0.5^{\mathrm{E}}$ \\
\hline PE11 & tr. & $1.360 \pm 0.054^{\mathrm{C}}$ & $2.91 \pm 0.12^{\mathrm{E}}$ & $1.67 \pm 0.08^{C}$ & $13.2 \pm 0.6^{\mathrm{D}}$ \\
\hline PE12 & n.d. & $4.026 \pm 0.081^{\mathrm{A}}$ & $2.43 \pm 0.15^{\mathrm{F}}$ & tr. & $13.4 \pm 0.7^{\mathrm{CD}}$ \\
\hline \multirow{2}{*}{$\mathrm{PE}^{\mathrm{a}}$} & \multicolumn{5}{|c|}{ QA Content (mg LE/g FL) ${ }^{b}$} \\
\hline & 8 & 9 & 11 & 12 & 13 \\
\hline PE1 & tr. & tr. & n.d. & $0.055 \pm 0.002^{\mathrm{B}}$ & $1.74 \pm 0.10^{\mathrm{F}}$ \\
\hline PE2 & tr. & $0.014 \pm 0.001^{\mathrm{F}}$ & n.d. & $0.076 \pm 0.003^{\mathrm{A}}$ & $1.86 \pm 0.15^{\mathrm{EF}}$ \\
\hline PE3 & tr. & $0.162 \pm 0.008^{\mathrm{B}}$ & n.d. & tr. & $1.42 \pm 0.08^{\mathrm{G}}$ \\
\hline PE4 & tr. & $0.132 \pm 0.009^{C}$ & n.d. & tr. & $1.57 \pm 0.09^{\mathrm{FG}}$ \\
\hline PE5 & $0.068 \pm 0.003^{\text {B }}$ & $0.051 \pm 0.006^{\mathrm{E}}$ & n.d. & tr. & $1.65 \pm 0.13^{\mathrm{F}}$ \\
\hline PE6 & $0.004 \pm 0.001^{\mathrm{C}}$ & $0.074 \pm 0.005^{\mathrm{D}}$ & n.d. & n.d. & $4.84 \pm 0.21^{\mathrm{B}}$ \\
\hline PE7 & $0.003 \pm 0.001^{\mathrm{C}}$ & $0.201 \pm 0.011^{\mathrm{A}}$ & tr. & n.d. & $14.7 \pm 0.5^{\mathrm{A}}$ \\
\hline PE8 & $0.149 \pm 0.012^{\mathrm{A}}$ & $0.088 \pm 0.001^{\mathrm{D}}$ & tr. & n.d. & $14.3 \pm 0.4^{\mathrm{A}}$ \\
\hline PE9 & tr. & n.d. & tr. & n.d. & $2.47 \pm 0.19^{\mathrm{D}}$ \\
\hline PE10 & n.d. & n.d. & $1.69 \pm 0.07^{\mathrm{A}}$ & n.d. & $2.10 \pm 0.14^{\mathrm{E}}$ \\
\hline PE11 & n.d. & n.d. & $1.52 \pm 0.06^{\mathrm{B}}$ & n.d. & $4.01 \pm 0.18^{\mathrm{C}}$ \\
\hline PE12 & n.d. & n.d. & $0.039 \pm 0.005^{C}$ & n.d. & $4.53 \pm 0.19^{\mathrm{BC}}$ \\
\hline
\end{tabular}

a PE = pruning events, i.e., twelve time periods for cutting off leaves from the same living, growing L. polyphyllus plants $(n=10) .{ }^{\mathrm{b}}$ Contents expressed as mg of lupanine equivalents per gram of fresh leaves (mg LE/g FL); the presented values comprise means \pm standard deviation $(n=10)$. Different uppercase capital letters indicate statistically significant differences according to the post hoc Tukey test $(p<0.05)$. n.d. $=$ not detected. tr. $=$ traces.

The QREs obtained from the twelve PE on L. polyphyllus were evaluated through mycelium growth inhibition tests at 5, 1, and $0.1 \mu \mathrm{g} / \mu \mathrm{L}$ (Figure 6). In general, the QREs from PE1-4 corresponded to mixtures that contained low amounts $(<14 \mathrm{mg} / \mathrm{g} \mathrm{fl})$ of compounds structurally related to 7 , and whose inhibition was $<80 \%$, while PE5-9 exhibited the combined high presence of 1, 9 and 13 (Figure 7A) which seemed to be responsible for the best activity, especially in PE7-8, whose inhibition was $>85 \%$. This fact is possible since these compounds were previously reported to exhibit antifungal activity against pathogens like Valsa pini, Cladosporium oxysporum, Sphaeropsis sapinea, Marssonina brunne, A. solani, M. fructicola, and F. oxysporum $[55,57]$. There was no substantial decrease in antifungal activity between PE10-12 and PE5-9, despite the absence of $\mathbf{1}$ and 9. However, the presence of 11, which is a hydroxylated derivative of 7 , has also been reported to have antimicrobial activity against E. coli, P. aeruginosa, B. subtilis, S. aureus, C. albicans, and C. krusei [21]. 


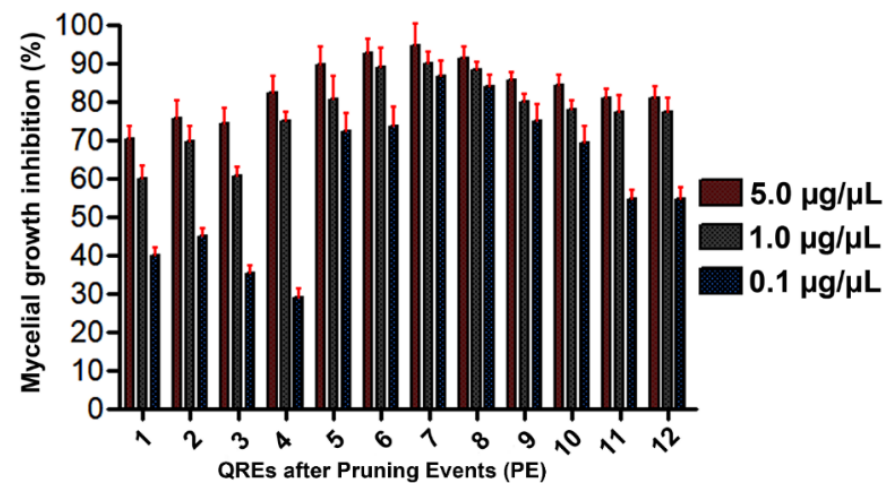

Figure 6. Mycelial growth inhibition percentages of QREs at three concentrations after pruning events (PE1-12) on L. polyphyllus.

(A)
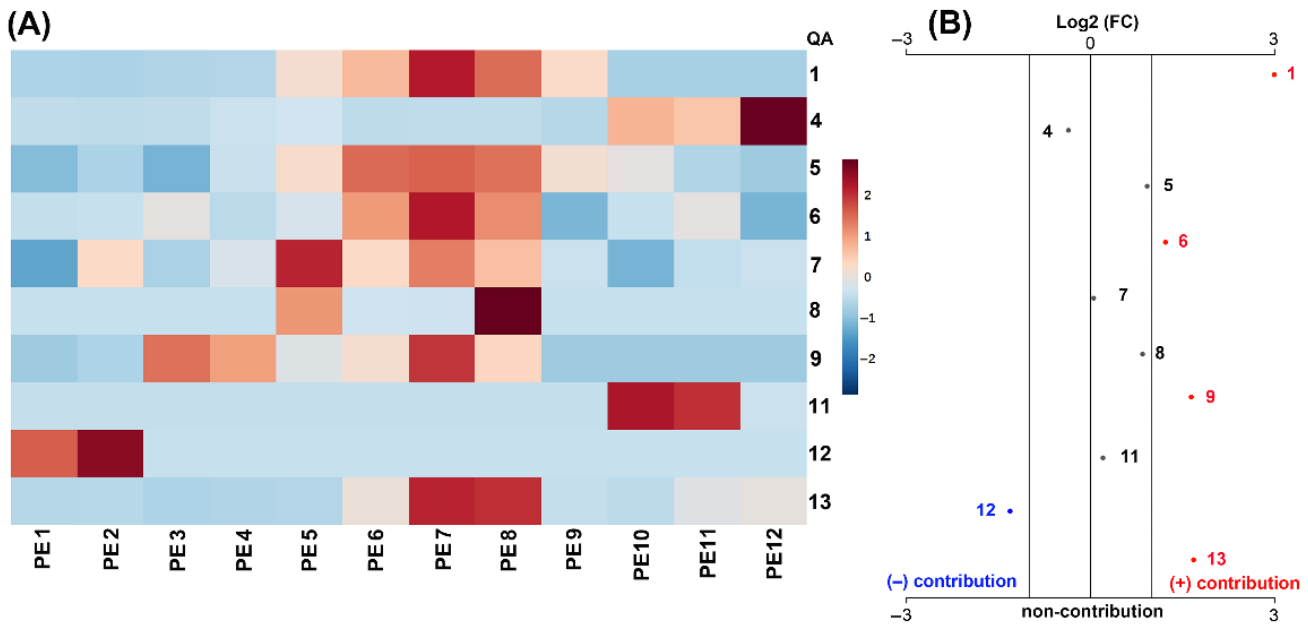

Figure 7. Comparison of quinolizidine alkaloid (QA) contents ( $\mathrm{mg} / \mathrm{g}$ fresh leaves) of quinolizidinerich extracts (QREs) obtained after twelve pruning events on L. polyphyllus. (A) Heatmap visualization of the normalized content distribution (unit of variance scaling) of quantified QAs of each resulting QRE. Autoscaled QA contents are related to the color scale: 2 = high content; $-2=$ low content. (B) Unpaired fold-change (FC) analysis plot for selecting important QAs with threshold 2, by integrating the chemical (QA contents) and biological (mycelial growth inhibition) data. Antifungal activity was used as a categorical variable, subdividing the antifungal activity of QREs into two datasets: more active ( $>90 \%$ inhibition) and less active ( $<85 \%$ inhibition), according to the Tukey test, to supervise the QA selection among QREs. According to the antifungal activity, positive and negative contributions to the FC-based QA selection are depicted as red and blue numbers and dots.

The unpaired FC analysis of the PE1-12-derived QREs showed that 1, 6, 9, and 13 contributed positively to the antifungal activity (Figure $7 \mathrm{~B}$ ), and the extracts containing these selected QAs would be promising mixtures to inhibit the growth of F. oxysporum under in vitro conditions, within the pruning-dependent natural supply of QA from $L$. polyphyllus. Hence, such mixtures and other variations for phytopathogen management and control at different scales can be explored.

There is a relevant concern about QA-rich lupin-based foods for human and animal consumption related to the acute anticholinergic toxicity of QAs, which encouraged several procedures for seed debittering and the development of lupin varieties that produce/accumulate low QA amounts [13,65]. Additionally, the QAs structurally related to $\mathbf{1 0}$ (i.e., 2-pyridone-containing tetracyclic QAs) have shown a teratogenic background. They are responsible for Holstein cattle's so-called twisted calf disease [66]. Therefore, although lupin QAs are recognized as natural defensive compounds (Wink, 2018), and this feature can be exploited for pest management, their development as chemical agents for controlling 
phytopathogens should be rationally and carefully conducted. In this regard, these findings can serve as a reference in future studies to explore the composition-activity (and even structure-activity) relationship of QAs to optimize such an antifungal potential and reduce possible side effects due to the toxicity.

\section{Materials and Methods}

\subsection{Propagation of Lupinus Plants under Greenhouse Conditions}

Seeds of the three native species, i.e., L. bogotensis Benth., L. mutabilis Sweet, and L. mirabilis C.P. Sm., were collected on the campus at Military University Nueva Granada (UMNG) $\left(4^{\circ} 56^{\prime} \mathrm{N}, 74^{\circ} 00^{\prime} \mathrm{W}\right.$ and 2562 masl). Seeds of five exotic species, i.e., L. albus L., $L$. argenteus Pursh, L. polyphyllus Lindl. "Russell", L. perennis L., and L. arboreus Sims, were commercially purchased from Sow Right Seeds (https:/ / sowrightseeds.com, accessed on 30 November 2021).

All the Lupinus seeds were superficially disinfected with $70 \%$ ethanol (2 min) and then with $3 \%$ sodium hypochlorite $(5 \mathrm{~min})$, subsequently washed with sterile distilled water $(3 \times 3 \mathrm{~min})$, and cleaned with a drop of Tween 20 . The seeds were planted in 72 -cell seedbeds that contained a substrate of loamy-silty soil (LSS) with rice husk ( $\mathrm{RiH})$ at a 3:1 ratio and were maintained under greenhouse conditions (temperature $=21 \pm 4{ }^{\circ} \mathrm{C}$; relative humidity $(\mathrm{RH})=65 \pm 15 \%$, altitude $=2562$ masl, total light transmission $=85 \pm 5 \%$, total light diffusion $=55 \pm 5 \%$, and UV transmission between 290-340 $\mathrm{nm}=5 \%$ ) during the whole propagation experiment (30 days). At 8-10 days after seed planting (dasp), the seeds started the germination process (i.e., seed coat breakdown) and subsequent embryonic root (radicle) growing. Cotyledons appeared between 12-15 dasp on average.

After 20-30 dasp, the first and second pairs of leaves emerged, and the resulting seedlings $(n=20)$ were transplanted in $2 \mathrm{~L}$ bags on a substrate containing a mixture of LSS/RiH 3:1 and maintained under the same greenhouse conditions. After transplanting, the seedlings were watered with water $(500 \mathrm{~mL})$ every two days, and once the elongation of the central axis began to be observed, we proceeded to apply commercial triple- 15 fertilizer (5\%). After $70 \pm 19$ days of development under these conditions (i.e., after transplanting) to reach the flowering stage, fresh leaves were collected for QA extraction.

In addition, a new set of plants of L. polyphyllus were propagated at the same greenhouse conditions. After 50 days of transplanting, leaves were removed every two weeks from the same living, growing plants $(n=10)$ and subsequently prepared for QA extraction. Each pruning event (PE) was performed at the same time of the day (i.e., 10 a.m.). This pruning process was repeated twelve times (PE1-PE12).

\subsection{Preparation of Quinolizidine-Rich Extracts (QREs)}

Fresh young leaves $(5 \mathrm{~g})$ of each biological replicate $(n=10)$ were extracted with 0.5 $\mathrm{M} \mathrm{HCl}(20 \mathrm{~mL})$ under stirring for $24 \mathrm{~h}$ at $130 \mathrm{rpm}$ in an orbital shaker. Subsequently, the acidic solution was filtered and alkalinized to $\mathrm{pH}=10$ with a $15 \%$ aqueous $\mathrm{NH}_{3}$ solution. Subsequently, liquid-liquid extraction was performed using chloroform to obtain an organic phase enriched in QAs. Finally, the solvent was removed by distillation under reduced pressure at $375 \mathrm{mbar}$ for $5 \mathrm{~min}$, and Lupinus QREs were then obtained.

\subsection{Gas Chromatography Coupled to Mass Spectrometry (GC-MS)}

The chromatographic profiles and mass spectra were obtained with a Thermo Trace 1300 equipped with a flame ionization detector (FID) and coupled to an ISQ LT mass spectrometer with a single quadrupole analyzer. For the analysis, an Rxi ${ }^{\circledR} 5$ Sil MS column (5\% diphenyl $/ 95 \%$ dimethylpolysiloxane, $60 \mathrm{~m}, 0.25 \mathrm{~mm} \mathrm{ID}$, and $0.25 \mu \mathrm{m}$ ) was used. A temperature program was implemented; the starting temperature was $120^{\circ} \mathrm{C}$, maintained for $2 \mathrm{~min}$, and then a $6{ }^{\circ} \mathrm{C} / \mathrm{min}$ program was applied until $300{ }^{\circ} \mathrm{C}$ and kept for $10 \mathrm{~min}$. The test QREs were prepared at $1 \mu \mathrm{g} / \mu \mathrm{L}$ in $\mathrm{CH}_{2} \mathrm{Cl}_{2}$ (GC-MS grade, SupraSolv ${ }^{\circledR}$ ). The injection volume was $1 \mu \mathrm{L}$ in split mode (split ratio $=30$ ). The transfer line temperature was $250{ }^{\circ} \mathrm{C}$, and the carrier gas was grade- 5 helium (flow $=1 \mathrm{~mL} / \mathrm{min}$ ). The ionization mode was the 
electronic impact (EI) at $70 \mathrm{eV}$. The retention indices (RI) were calculated using a series of $\mathrm{C}_{10}-\mathrm{C}_{24} n$-alkanes [67], according to Equation (S1) (supplementary material). Compounds 1-13 were identified by diagnostic analysis of their mass spectra and comparison of RIs with available literature. On the other hand, the QAs quantification was performed using the external standard method by GC-FID under the same chromatographic conditions. The standard curve was built by injecting eight solutions (ranging from 1 to $500 \mu \mathrm{g} / \mathrm{mL}$ ) of (+)-lupanine $(100 \mu \mathrm{g} / \mathrm{mL}$, Sigma-Aldrich, St. Louis, MO, USA). The instrument response was verified by adding caffeine (100 $\mu \mathrm{g} / \mathrm{mL}$, Sigma-Aldrich, St. Louis, MO, USA) as an internal standard. Owing to limitations related to commercial availability or purity degree of reference compounds of identified QAs compounds, 1-13 were quantified as lupanine equivalents and expressed as $\mathrm{mg}$ lupanine equivalents per gram of fresh leaves ( $\mathrm{mg} \mathrm{LE} / \mathrm{g} \mathrm{fl}$ ). Relative response factors were used to correct the peak areas of detected QAs. Quantitative analysis was performed in triplicate. The intra and inter-day analyzes of (+)-lupanine were used to evaluate the method precision, whose relative standard deviations (RSD \%) were 2.4 and $3.7 \%$, respectively. The limit of detection (LOD) and limit of quantification (LOQ) of (+)-lupanine was 1 and $2 \mu \mathrm{g} / \mathrm{mL}$, respectively. Finally, the GC-MS-derived data were processed in MZmine 2 software to compare the resulting chromatographic profiles of QREs. Thus, the baseline correction was performed and exported as total ionic current (TIC) to a CSV file. Data were normalized and autoscaled. The resulting autoscaled profiles were stacked in OriginPro 8.5 for intuitive visualization of the QA variations between each QRE.

\subsection{Direct Bioautography Assay}

A spore suspension of the fungus F. oxysporum was prepared at a concentration of $1 \times$ $10^{6} \mathrm{CFU} / \mathrm{mL}$ on a nutrient broth containing $\mathrm{KH}_{2} \mathrm{PO}_{4}(7 \mathrm{~g}), \mathrm{Na}_{2} \mathrm{HPO}_{4} \cdot 2 \mathrm{H}_{2} \mathrm{O}(3 \mathrm{~g}), \mathrm{KNO}_{3}(4$ $\mathrm{g}), \mathrm{MgSO}_{4} \cdot 7 \mathrm{H}_{2} \mathrm{O}(1 \mathrm{~g})$, and $\mathrm{NaCl}(1 \mathrm{~g})$ per liter of water. The culture broth was sterilized for $1 \mathrm{~h}$ in an autoclave at $120^{\circ} \mathrm{C}$. Then the spore suspension was prepared, adding $30 \%$ glucose $(10 \mathrm{~mL})$ for every $60 \mathrm{~mL}$ standard solution. Respective QRE solutions were prepared in $\mathrm{CHCl}_{3}$ at $1 \mathrm{mg} / \mathrm{mL}$. Subsequently, the QRE solutions $(50 \mu \mathrm{L})$ were seeded on silica gel $60 \mathrm{~F}_{254}$ thin-layer chromatography (TLC) plates $(20 \times 20 \mathrm{~cm}, 0.20 \mathrm{~mm}$ layer thickness, subdivided into squares), and the solvent was removed in an extraction chamber. Then, the spore solution of F. oxysporum was sprayed on the plate surface and placed into a humid and dark chamber at $25^{\circ} \mathrm{C}$ for $72 \mathrm{~h}$. Dithane (mancozeb) and Rovral (iprodione) were used as positive controls at the same doses. In this test, the antifungal activity was determined by light areas on the squares that indicated no fungal growth by inhibiting spore germination, contrasted with dark areas that revealed fungal growth [68].

\subsection{Mycelial Growth Inhibition Assay}

Antifungal activity evaluation of QREs was performed by measuring the growth halo of the phytopathogen $F$. oxysporum with the presence of the extracts at different concentrations compared to that of a blank (0.5\% PDA), using the amended-medium procedure [69]. The culture medium contained 2.4\% PDB and 1.5\% bacteriological agar in $100 \mathrm{~mL}$ of distilled water. The medium was homogenized for $2 \mathrm{~min}$ in a microwave oven and then sterilized in an autoclave for $1 \mathrm{~h}$ at $120^{\circ} \mathrm{C}$. The culture medium $(20 \mathrm{~mL})$ was then placed into a previously sterilized Petri dish to propagate the fungus. Once it cooled and solidified, a 2-mm plug from a previously prepared monosporic culture was placed onto the central part of the Petri dish and left to grow at $28^{\circ} \mathrm{C}$ for 8 days.

Three treatments per QRE were prepared for the antifungal assays according to three final QRE concentrations (i.e., 5, 1, and $0.1 \mu \mathrm{g} / \mu \mathrm{L}$ ). Thus, the required amount of the respective QRE was dispersed in $0.5 \%$ PDA to afford the QRE-amended medium per treatment. Subsequently, each treatment was randomly placed in a 12-well glass plate (79 $\times 63 \times 4 \mathrm{~mm}$ ). Finally, a 1.1-mm plug (equivalent to the internal diameter of a 1.1-mm borosilicate capillary tube) was taken from an 8-day phytopathogen culture and placed onto the center of each well (QRE-amended and non-amended). This plate was placed 
into a humid chamber for $72 \mathrm{~h}$ at $25^{\circ} \mathrm{C}$. The evaluation of each concentration per QRE treatment was performed in triplicate. Dithane (mancozeb) and Rovral (iprodione) were used as positive controls at the same doses. After the incubation time, a photograph of the 12-well plate was taken and analyzed in ImageJ software, whose growth areas of control (non-amended) and QRE-amended wells were measured. The comparison of these areas led to the determination of the inhibition percentage using Equation (1).

$$
\text { Inhibition Percentage }=\frac{\text { area }_{\text {control }}-\text { area }_{\mathrm{QRE}}}{\text { area }_{\text {control }}} \times 100 \%
$$

\subsection{Fungicidal (FC) and Fungistatic (FS) Activity}

For the fungicidal or fungistatic activity classification procedure, the central plug of the phytopathogen used in the prior $5-\mu \mathrm{g} / \mu \mathrm{L}$-amended treatment was retrieved and placed onto fresh, non-amended PDA medium for $72 \mathrm{~h}$. After this time, mycelial growth was additionally monitored. The QRE was classified as fungistatic or fungicidal if mycelial growth or no mycelial growth, respectively, was observed [70].

\subsection{Data Analysis}

A Shapiro-Wilks normality test was accomplished to examine the normal distribution of the quantitative data $(p>0.05)$. Once the normal distribution of the data was verified, an analysis of variance (ANOVA) was subsequently performed, followed by a post hoc Tukey test to establish significant differences between samples $(p<0.05)$. These analyses were performed in Infostat statistical software [71]. In addition, a heatmap was constructed using normalized QA contents through autoscaling. The antifungal activity was subsequently divided into two datasets (i.e., more and less active) depending on the significantly different mean groups after the Tukey test. An unpaired fold-change analysis (threshold = 2) was finally performed on chemical and antifungal activity datasets to select important QAs that positively and negatively contribute to mycelial growth inhibition.

\section{Conclusions}

The present study attempts to combine the information of QA profiles and the antifungal activities against F. oxysporum of lupin derived QREs. This chemical and antifungal dataset integration provided valuable information of naturally afforded QA mixtures to understand the promising concomitant effects against F. oxysporum. In summary, we found that the test QREs showed important antifungal activity since all extracts showed inhibition $>50 \%$ at the maximum test concentration $(5 \mu \mathrm{g} / \mu \mathrm{L})$. The best antifungal results were obtained for the QREs of L. mirabilis, L. polyphyllus "Russell", and L. bogotensis, reaching inhibitions $\geq 90 \%$ and similar to positive controls. In addition, all QREs were classified as fungistatic except for the L. polyphyllus-derived QRE ranked as a fungicide. QREs obtained after twelve pruning events on L. polyphyllus exhibited antifungal activity variations, with the QREs derived from PE7-8 being the most active extracts. Each test extract in the present study showed differential QA profiles. In-depth qualitative and quantitative analysis of such QA differences indicated that QREs containing particular combinations of angustifoline (4), $\alpha$-isolupanine (6), matrine (9), 13 $\alpha$-hydroxylupanine (11), and 17-oxolupanine (13) best inhibit the growth of F. oxysporum. Contrarily, lupanine (7) seems to have a low contribution to the antifungal activity despite its high abundance in test QREs. A better understanding of such bioactivity of QA mixtures would promote further studies to deeply understand and exploit their antifungal potential at different levels (i.e., greenhouse and field conditions) for managing and controlling F. oxysporum within IPM programs.

Supplementary Materials: The following supporting information can be downloaded online. Table S1: Yields of QREs obtained from propagated Lupinus species under greenhouse, Table S2: Replicates of the mycelial growth inhibition percentages of each lupin-based treatment, Figure S1: structures of QA identified in the eight species of Lupinus, Figure S2: Antifungal activity against $F$. oxysporum of eight Lupinus species, and Equation (S1): Retention index calculation. 


\begin{abstract}
Author Contributions: Conceptualization, E.C.-B.; methodology, W.C.-V.; software, W.C.-V. and E.C.-B.; validation, W.C.-V., D.Q. and E.C.-B.; formal analysis, W.C.-V. and E.C.-B.; resources, D.Q. and E.C.-B.; data curation, W.C.-V. and E.C.-B.; writing-original draft preparation, W.C.-V.; writingreview and editing, W.C.-V., D.Q. and E.C.-B.; supervision, E.C.-B.; project administration, E.C.-B.; funding acquisition, D.Q. and E.C.-B. All authors have read and agreed to the published version of the manuscript.
\end{abstract}

Funding: This study was funded by the Vicerrectoría de Investigaciones at Universidad Militar Nueva Granada through the project IMP-CIAS-2924, validity 2019.

Institutional Review Board Statement: Not applicable.

Informed Consent Statement: Not applicable.

Data Availability Statement: The data that support the findings of this study are available from the corresponding author upon reasonable request.

Acknowledgments: Authors thank the Universidad Militar Nueva Granada for the financial support.

Conflicts of Interest: The authors declare no conflict of interest.

Sample Availability: Samples of the substances are available from the corresponding author upon reasonable request.

\title{
References
}

1. Krishna, P.M.; Rao, K.N.V.; Sandhya, S.; Banji, D. A review on phytochemical, ethnomedical and pharmacological studies on genus Sophora, Fabaceae. Braz. J. Pharmacogn. 2012, 22, 1145-1154. [CrossRef]

2. Wink, M. Evolution of secondary metabolites in legumes (Fabaceae). S. Afr. J. Bot. 2013, 89, 164-175. [CrossRef]

3. Confortin, T.C.; Todero, I.; Soares, J.F.; Brun, T.; Luft, L.; Ugalde, G.A.; Prá, V.D.; Mazutti, M.A.; Zabot, G.L.; Tres, M.V. Extraction and composition of extracts obtained from Lupinus albescens using supercritical carbon dioxide and compressed liquefied petroleum gas. J. Supercrit. Fluids 2017, 128, 395-403. [CrossRef]

4. Kole, C. Wild Crop Relatives: Genomic and Breeding Resources. Legume Crops and Forages; Springer: Berlin/Heidelberg, Germany, 2011; ISBN 9783642143878.

5. Gresta, F.; Wink, M.; Prins, U.; Abberton, M.; Capraro, J.; Scarafoni, A.; Hill, G. Lupins in European Cropping Systems. In Legumes in Cropping Systems; Murphy-Bokern, D., Stoddard, F., Watson, C., Eds.; CABI Publishing: Wallingford, CT, USA, 2017; pp. 88-108.

6. Contreras-Ortiz, N.; Jara-Muñoz, O.A.; Hughes, C.E. The acaulescent rosette species of Lupinus L. (Fabaceae) of Colombia and Ecuador including a new species from Colombia. Phytotaxa 2018, 364, 61-70. [CrossRef]

7. Lucas, M.M.; Stoddard, F.; Annicchiarico, P.; Frias, J.; Martinez-Villaluenga, C.; Sussmann, D.; Duranti, M.; Seger, A.; Zander, P.; Pueyo, J. The future of lupin as a protein crop in Europe. Front. Plant Sci. 2015, 6, 705. [CrossRef]

8. Cortés-Avendaño, P.; Tarvainen, M.; Suomela, J.P.; Glorio-Paulet, P.; Yang, B.; Repo-Carrasco-Valencia, R. Profile and content of residual alkaloids in ten ecotypes of Lupinus mutabilis Sweet after aqueous debittering process. Plant Foods Hum. Nutr. 2020, 75, 184-191. [CrossRef] [PubMed]

9. Wink, M. Introduction: Biochemistry, Physiology and Ecological Functions of Secondary Metabolites. In Biochemistry of Plant Secondary Metabolism; Wiley-Blackwell: Oxford, UK, 2010; Volume 40, pp. 1-19. ISBN 9781444320503.

10. Hernández, E.M.; Rangel, M.L.C.; Corona, A.E.; del Angel, J.A.C.; López, J.A.S.; Sporer, F.; Wink, M.; Torres, K.B. Quinolizidine alkaloid composition in different organs of Lupinus aschenbornii. Rev. Bras. Farmacogn. 2011, 21, 824-828. [CrossRef]

11. Neto, A.T.; Oliveira, C.Q.; Ilha, V.; Pedroso, M.; Burrow, R.A.; Dalcol, I.I.; Morel, A.F. Quinolizidine alkaloids from Lupinus lanatus. J. Mol. Struct. 2011, 1004, 174-177. [CrossRef]

12. Aisyah, S.; Vincken, J.P.; Andini, S.; Mardiah, Z.; Gruppen, H. Compositional changes in (iso)flavonoids and estrogenic activity of three edible Lupinus species by germination and Rhizopus-elicitation. Phytochemistry 2016, 122, 65-75. [CrossRef]

13. Frick, K.M.; Kamphuis, L.G.; Siddique, K.H.M.; Singh, K.B.; Foley, R.C. Quinolizidine alkaloid biosynthesis in Lupins and prospects for grain quality improvement. Front. Plant Sci. 2017, 8, 87. [CrossRef]

14. Boschin, G.; Resta, D. Alkaloids Derived from Lysine: Quinolizidine (a focus on Lupin alkaloids) BT-Natural products: Phytochemistry, botany and metabolism of alkaloids, phenolics and terpenes. In Natural Products. Phytochemistry, Botany and Metabolism of Alkaloids, Phenolics and Terpenes; Ramawat, K.G., Mérillon, J.-M., Eds.; Springer: Berlin/Heidelberg, Germany, 2013; pp. 381-403. ISBN 978-3-642-22144-6.

15. Wink, M. Plant secondary metabolites modulate insect behavior-steps toward addiction? Front. Physiol. 2018, 9, 364. [CrossRef]

16. Arias Alemán, L.S.E.; Ulloa Ramones, L.A.; Rojas Oviedo, L.A.; Noboa Abdo, T.E. Effect of alkaloids of Lupinus mutabilis Sweet on gastrointestinal parasites in guinea pigs. Cienc. Digit. 2019, 3, 221-228. [CrossRef]

17. Wink, M. Chemical defense of Lupins. Mollusc-repellent properties of Quinolizidine Alkaloids. Z. Naturforsch. C 1984, 39, 553-558. [CrossRef] 
18. Romeo, F.; Fabroni, S.; Ballistreri, G.; Muccilli, S.; Spina, A.; Rapisarda, P. Characterization and antimicrobial activity of alkaloid extracts from seeds of different genotypes of Lupinus spp. Sustainability 2018, 10, 788. [CrossRef]

19. Ohadoma, S.C.; Nnatuanya, I.; Amazu, L.U.; Okolo, C.E. Antimicrobial activity of the leaf extract and fractions of Lupinus arboreus. J. Med. Plants Res. 2014, 8, 386-391. [CrossRef]

20. Confortin, T.C.; Todero, I.; Soares, J.F.; Luft, L.; Brun, T.; Rabuske, J.E.; Nogueira, C.U.; Mazutti, M.A.; Zabot, G.L.; Tres, M.V. Extracts from Lupinus albescens: Antioxidant power and antifungal activity in vitro against phytopathogenic fungi. Environ. Technol. 2019, 40, 1668-1675. [CrossRef] [PubMed]

21. Erdemoglu, N.; Ozkan, S.; Tosun, F. Alkaloid profile and antimicrobial activity of Lupinus angustifolius L. alkaloid extract. Phytochem. Rev. 2007, 6, 197-201. [CrossRef]

22. El-Shazly, A.; Ateya, A.M.; Wink, M. Quinolizidine alkaloids profiles of Lupinus varius orientalis, L. albus albus, L. hartweguii and L. desinflorus. Z. Naturforsch. C 2001, 56, 21-30. [CrossRef] [PubMed]

23. Bernal-Alcocer, A.; Zamora-Natera, J.F.; Virgen-calleros, G.; Nuño-romero, R. In vitro biological activity of extracts of Lupinus spp. on phytopathogenic fungi. Rev. Mex. Fitopatol. 2005, 23, 140-146.

24. Pegg, K.G.; Coates, L.M.; O’Neill, W.T.; Turner, D.W. The epidemiology of Fusarium wilt of banana. Front. Plant Sci. 2019, 10, 1395. [CrossRef]

25. Edel-Hermann, V.; Lecomte, C. Current status of Fusarium oxysporum formae speciales and races. Phytopathology 2019, 109, 512-530. [CrossRef] [PubMed]

26. Giraldo-Betancourt, C.; Velandia-Sánchez, E.A.; Fischer, G.; Gómez-Caro, S.; Martínez, L.J. Hyperspectral response of cape gooseberry (Physalis peruviana L.) plants inoculated with Fusarium oxysporum $\mathrm{f}$. sp. physali for vascular wilt detection. Rev. Colomb. Cienc. Hortic. 2020, 14, 301-313. [CrossRef]

27. García-Bastidas, F.A.; Quintero-Vargas, J.C.; Ayala-Vasquez, M.; Schermer, T.; Seidl, M.F.; Santos-Paiva, M.; Noguera, A.M.; Aguilera-Galvez, C.; Wittenberg, A.; Hofstede, R.; et al. First report of Fusarium wilt tropical race 4 in cavendish bananas caused by Fusarium odoratissimum in Colombia. Plant Dis. 2020, 104, 994. [CrossRef]

28. Basallote-Ureba, M.J.; Vela-Delgado, M.D.; Capote, N.; Melero-Vara, J.M.; López-Herrera, C.J.; Prados-Ligero, A.M.; TalaveraRubia, M.F. Control of Fusarium wilt of carnation using organic amendments combined with soil solarization, and report of associated Fusarium species in southern Spain. Crop Prot. 2016, 89, 184-192. [CrossRef]

29. Jangir, M.; Pathak, R.; Sharma, S.; Sharma, S. Biocontrol mechanisms of Bacillus sp., isolated from tomato rhizosphere, against Fusarium oxysporum f. sp. lycopersici. Biol. Control 2018, 123, 60-70. [CrossRef]

30. Amini, J.; Dzhalilov, F.S. The effects of fungicides on Fusarium oxysporum f. sp. lycopersici associated with Fusarium wilt of tomato. J. Plant Prot. Res. 2010, 50, 172-178. [CrossRef]

31. Ajilogba, C.F.; Babalola, O.O. Integrated management strategies for tomato Fusarium Wilt. Biocontrol Sci. 2013, 18, 117-127. [CrossRef]

32. Hernández Martínez, R.; López Benítez, A.; Borrego Escalante, F.; Espinoza Velázquez, J.; Sánchez Aspeytia, D.; Maldonado Mendoza, I.E.; López Ochoa, L.A. Races of Fusarium oxysporum f. sp. lycopersici in tomato farmlands in San Luis Potosí. Rev. Mex. Cienc. Agrícolas 2018, 5, 1169. [CrossRef]

33. Petz, W.; Foissner, W. The effects of mancozeb and lindane on the soil microfauna of a spruce forest: A field study using a completely randomized block design. Biol. Fertil. Soils 1989, 7, 225-231. [CrossRef]

34. Walia, A.; Mehta, P.; Guleria, S.; Chauhan, A.; Shirkot, C.K. Impact of fungicide mancozeb at different application rates on soil microbial populations, soil biological processes, and enzyme activities in soil. Sci. World J. 2014, 2014, 702909. [CrossRef]

35. Adhikari, K.N.; Buirchell, B.J.; Sweetingham, M.W. Length of vernalization period affects flowering time in three lupin species. Plant Breed. 2012, 131, 631-636. [CrossRef]

36. Clapham, W.L.; Willcott, J.B. A Thermosensitivity index for Lupinus albus L. Crop Sci. 1999, 39, 578-580. [CrossRef]

37. Podleśny, J.; Podleśna, A. The effect of high temperature during flowering on growth, development and yielding of blue lupine-barley mixture. J. Food Agric. Environ. 2012, 10, 500-504.

38. Li, Y.; Kong, D.; Fu, Y.; Sussman, M.R.; Wu, H. The effect of developmental and environmental factors on secondary metabolites in medicinal plants. Plant Physiol. Biochem. 2020, 148, 80-89. [CrossRef]

39. Przybylak, J.K.; Ciesiołka, D.; Wysocka, W.; García-López, P.M.; Ruiz-López, M.A.; Wysocki, W.; Gulewicz, K. Alkaloid profiles of Mexican wild lupin and an effect of alkaloid preparation from Lupinus exaltatus seeds on growth and yield of paprika (Capsicum annuum L.). Ind. Crop. Prod. 2005, 21, 1-7. [CrossRef]

40. Cook, D.; Lee, S.T.; Gardner, D.R.; Pfister, J.A.; Welch, K.D.; Green, B.T.; Davis, T.Z.; Panter, K.E. The alkaloid profiles of Lupinus sulphureus. J. Agric. Food Chem. 2009, 57, 1646-1653. [CrossRef]

41. McDougal, O.M.; Heenan, P.B.; Jaksons, P.; Sansom, C.E.; Smallfield, B.M.; Perry, N.B.; van Klink, J.W. Alkaloid variation in New Zealand kōwhai, Sophora species. Phytochemistry 2015, 118, 9-16. [CrossRef]

42. Martínez-Herrera, J.; Robledo-Quintos, N.; Mora-Escobedo, R.; Dávila-Ortíz, G. Alkaloid composition of Lupinus campestris from Mexico. J. Food Biochem. 2001, 25, 117-125. [CrossRef]

43. Kianbakht, S.; Dabaghian, F.H. Sophora alopecuroides L. var. alopecuroides alleviates morphine withdrawal syndrome in mice: Involvement of alkaloid fraction and matrine. Iran. J. Basic Med. 2016, 19, 1090-1095. 
44. Basilico, N.; Parapini, S.; Sparatore, A.; Romeo, S.; Misiano, P.; Vivas, L.; Yardley, V.; Croft, S.L.; Habluetzel, A.; Lucantoni, L.; et al. In vivo and in vitro activities and ADME-tox profile of a quinolizidine-modified 4-aminoquinoline: A potent anti-P. falciparum and Anti-P. vivax blood-stage antimalarial. Molecules 2017, 22, 2102. [CrossRef]

45. Wink, M.; Carey, D.B. Variability of quinolizidine alkaloid profiles of Lupinus argentous (Fabaceae) from North America. Biochem. Syst. Ecol. 1994, 22, 663-669. [CrossRef]

46. Adler, L.S.; Kittelson, P.M. Variation in Lupinus arboreus alkaloid profiles and relationships with multiple herbivores. Biochem. Syst. Ecol. 2004, 32, 371-390. [CrossRef]

47. Kroc, M.; Rybiński, W.; Wilczura, P.; Kamel, K.; Kaczmarek, Z.; Barzyk, P.; Święcicki, W. Quantitative and qualitative analysis of alkaloids composition in the seeds of a white lupin (Lupinus albus L.) collection. Genet. Resour. Crop Evol. 2017, 64, 1853-1860. [CrossRef]

48. Vargas-Medina, L.; Yamaguchi, L.F.; Coy-Barrera, E. LC-ESI-HRMS-based Chemical characterization of Lupinus bogotensis roots Rev. Fac. Cienc. Basic. 2016, 12, 200-211. [CrossRef]

49. Wink, M.; Witte, L. Quinolizidine alkaloids in Genista acanthoclada and its holoparasite, Cuscuta palaestina. J. Chem. Ecol. 1993, 19, 441-448. [CrossRef]

50. Kacem, N.; Goossens, J.-F.; Duhal, N.; Roumy, V.; Hennebelle, T.; Christen, P.; Hostettmann, K.; Rhouati, S. Determination of alkaloids in endemic Genista quadriflora Munby (Fabaceae). Biochem. Syst. Ecol. 2014, 56, 83-87. [CrossRef]

51. Choma, I.; Jesionek, W. Effects-directed biological detection. In Instrumental Thin-Layer Chromatography; Elsevier: Amsterdam, The Netherlands, 2015; pp. 279-312. ISBN 9780124172845.

52. Dewanjee, S.; Gangopadhyay, M.; Bhattacharya, N.; Khanra, R.; Dua, T.K. Bioautography and its scope in the field of natural product chemistry. J. Pharm. Anal. 2015, 5, 75-84. [CrossRef] [PubMed]

53. Zamora-Natera, J.F.; Bernal-alcocer, A.; Ruiz-lópez, M.; Soto-hernández, M.; Vibrans-lindemann, H. Alkaloid profile of seeds from Lupinus exaltatus Zucc. (Fabaceae) and the antifungal evaluation of alkaloid extract and lupanin against phytopathogens. Rev. Mex. Fitopatol. 2005, 23, 124-129.

54. Kwaśniewska, P.W.; Cofta, G.; Mazela, B.; Gobakken, L.R.; Przybył, A.K. Fungistatic activity of quinolizidine and bisquinolizidine alkaloids against A. niger. Int. Res. Gr. Wood Prot. 2016, 47, 1-9.

55. Yang, X.; Zhao, B. Antifungal activities of matrine and oxymatrine and their synergetic effects with chlorthalonil. J. For. Res. 2006, 17, 323-325. [CrossRef]

56. Zamora-Natera, F.; García-López, P.; Ruiz-López, M.; Salcedo-Pérez, E. Composition of alkaloids in seeds of Lupinus mexicanus (Fabaceae) and antifungal and allelopathic evaluation of the alkaloid extract. Agrociencia 2008, 42, 185-192.

57. Pérez-Laínez, D.; García-Mateos, R.; San Miguel-Chávez, R.; Soto-Hernández, M.; Rodríguez-Pérez, E.; Kite, G. Bactericidal and fungicidal activities of Calia secundiflora (Ort.) Yakovlev. Z. Naturforsch. C 2008, 63, 653-657. [CrossRef]

58. Shao, J.; Wang, T.; Yan, Y.; Shi, G.; Cheng, H.; Wu, D.; Wang, C. Matrine reduces yeast-to-hypha transition and resistance of a fluconazole-resistant strain of Candida albicans. J. Appl. Microbiol. 2014, 117, 618-626. [CrossRef]

59. Goto, T.; Hirazawa, N.; Takaishi, Y.; Kashiwada, Y. Antiparasitic effect of matrine and oxymatrine (quinolizidine alkaloids) on the ciliate Cryptocaryon irritans in the red sea bream Pagrus major. Aquaculture 2015, 437, 339-343. [CrossRef]

60. He, H.; Qin, X.; Dong, F.; Ye, J.; Xu, C.; Zhang, H.; Liu, Z.; Lv, X.; Wu, Y.; Jiang, X.; et al. Synthesis, characterization of two matrine derivatives and their cytotoxic effect on Sf9 cell of Spodoptera frugiperda. Sci. Rep. 2020, 10, 17999. [CrossRef]

61. ur Rashid, H.; Xu, Y.; Muhammad, Y.; Wang, L.; Jiang, J. Research advances on anticancer activities of matrine and its derivatives: An updated overview. Eur. J. Med. Chem. 2019, 161, 205-238. [CrossRef]

62. Yang, Y.; Xiu, J.; Zhang, X.; Zhang, L.; Yan, K.; Qin, C.; Liu, J. Antiviral effect of matrine against human enterovirus 71. Molecules 2012, 17, 10370-10376. [CrossRef] [PubMed]

63. Lin, Z.; Huang, C.F.; Liu, X.S.; Jiang, J. In vitro anti-tumour activities of quinolizidine alkaloids derived from Sophora flavescens Ait. Basic Clin. Pharmacol. Toxicol. 2011, 108, 304-309. [CrossRef]

64. Liu, W.; Shi, J.; Zhu, L.; Dong, L.; Luo, F.; Zhao, M.; Wang, Y.; Hu, M.; Lu, L.; Liu, Z. Reductive metabolism of oxymatrine is catalyzed by microsomal CYP3A4. Drug Des. Devel. Ther. 2015, 9, 5771-5783. [CrossRef] [PubMed]

65. Schrenk, D.; Bodin, L.; Chipman, J.K.; Del Mazo, J.; Grasl-Kraupp, B.; Hogstrand, C.; Hoogenboom, L.R.; Leblanc, J.-C.; Nebbia, C.S.; Nielsen, E.; et al. Scientific opinion on the risks for animal and human health related to the presence of quinolizidine alkaloids in feed and food, in particular in lupins and lupin-derived products. Eur. Food Saf. Auth. J. 2019, 17, e05860.

66. Green, B.T.; Lee, S.T.; Welch, K.D.; Cook, D. Anagyrine desensitization of peripheral nicotinic acetylcholine receptors. A potential biomarker of quinolizidine alkaloid teratogenesis in cattle. Res. Vet. Sci. 2017, 115, 195-200. [CrossRef] [PubMed]

67. Babushok, V.I. Chromatographic retention indices in identification of chemical compounds. TrAC-Trends Anal. Chem. 2015, 69, 98-104. [CrossRef]

68. Marques, J.V.; Kitamura, R.O.S.; Lago, J.H.G.; Young, M.C.M.; Guimarães, E.F.; Kato, M.J. Antifungal amides from Piper scutifolium and Piper hoffmanseggianum. J. Nat. Prod. 2007, 70, 2036-2039. [CrossRef] [PubMed]

69. Marentes-Culma, R.; Orduz-Díaz, L.L.; Coy-Barrera, E. Targeted metabolite profiling-based identification of antifungal 5- $n$ alkylresorcinols occurring in different cereals against Fusarium oxysporum. Molecules 2019, 24, 770. [CrossRef] [PubMed]

70. Cole, M.D. Key antifungal, antibacterial and anti-insect assays-A critical review. Biochem. Syst. Ecol. 1994, 22, 837-856. [CrossRef]

71. Di Rienzo, J.A.; Casanoves, F.; Balzarini, M.G.; Gonzalez, L.; Tablada, M.; Robledo, C.W. InfoStat Version 24. Available online: http:/ / www.infostat.com.ar/ (accessed on 12 November 2021). 